\title{
المحدد الديني للحضارة والسياسات العالمية: \\ قراءة في منظور الفاروقي للعلاقات الدولية
}

\section{*}

عبد القادر عبد العالي - مبل

$$
\begin{aligned}
& \text { ملخص } \\
& \text { يعرض البحث منظور إبماعيل الفاروقي لدور الدين في السياسات العالمية الراهنة، ويرسم ملامح نظرية معيارية }
\end{aligned}
$$

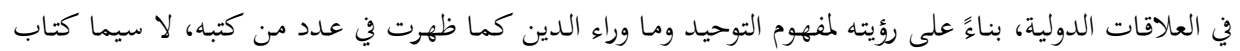

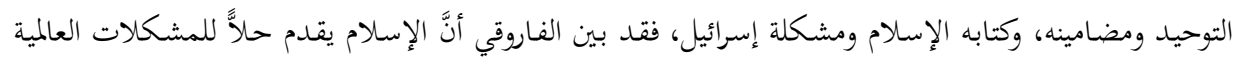

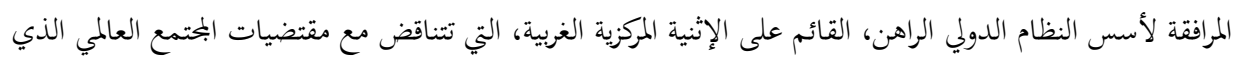

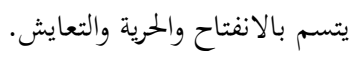

$$
\begin{aligned}
& \text { الكلمات المفتاحية :إبماعيل الفاروقي، الحضارة اليهودية-المسيحية، السياسة الدولية، النظرية المعيارية، ما وراء } \\
& \text { الدين، الإثنية المركزية، الأُمَّية النظام الدولي، السلام الإسلامي. }
\end{aligned}
$$

\section{Abstract \\ The Religious Determinant for Civilization and Global Policies: A Reading of Al- Faruqi's Perspective on International Relations}

This paper presents the perspective of Ismail al-Faruqi on the role of religion in current international politics, and lays out the features of a normative theory in international relations based on his view of the concepts of Tawhid and meta-religion as presented in a number of his books, particularly "Tawhid: Implications for Thought and Life" and "Islam and the Problem of Israel." Al-Faruqi elucidates how Islam offers solutions to global problems associated with the foundations of the current international system, which is based on the ethno-Euro-centricity, a system that contradicts the needs of the global society, which in turn is characterized by openness, freedom, and coexistence.

Keywords: Ismail al-Faruqi, Judeo-Christian Civilization, International Politics, Normative theory, meta-religion, Ethno-centricity, Ummatism, The International System, Islamic Peace (pax islamica).

$$
\begin{aligned}
& \text { * دكتوراه في العلوم السياسية، أستاذ محاضر بقسم العلوم السياسية والعلاقات الدولية بكلية الحقوق والعلوم السياسية، }
\end{aligned}
$$

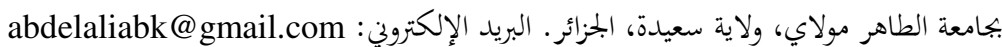

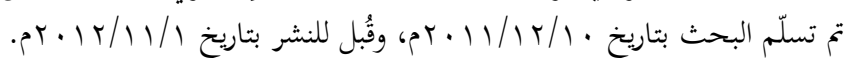


تتنـاول الدراسـة عرض ومناقشـة منظور المرحسوم إسماعيل راجي الفـاروقي للعلاقـات

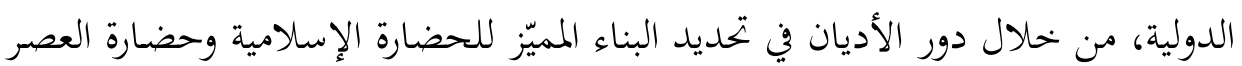
الراهن، وأثرها على تشكيل السياسات العالمية الراهنة والعلاقات الدولية، وكيف تسمح

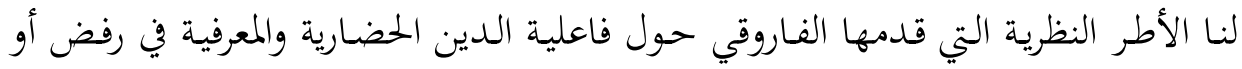
تعديل فرضيات وأطروحات صدام الحضارات والصراع مع الإسلام، التي يروج لها الفكر

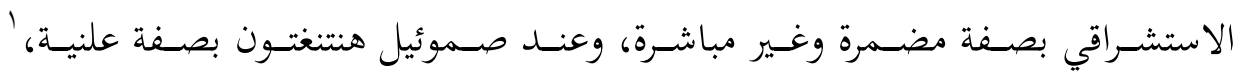
وأطروحات التخويف من الإسلام (الإسلاموفوبيا) ومزاعم اضطهاده للأقليـات، وقيامـهـ

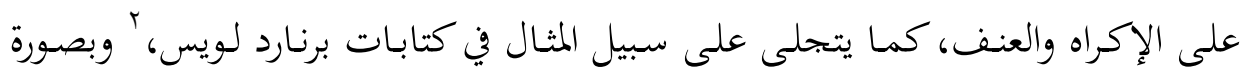

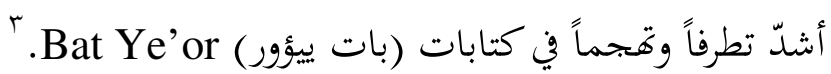

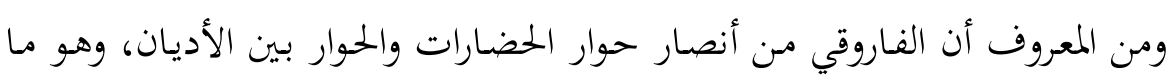

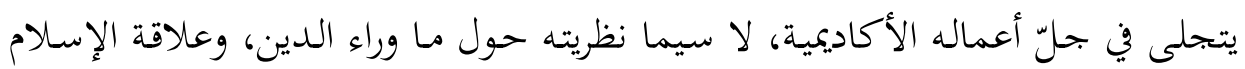

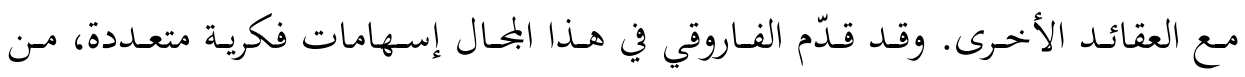
خلال المقالات والكتب التي ألّفها. ولعل من الإسهامات المهمة التي تركها، إسهاماته في

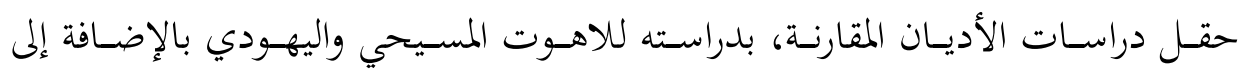

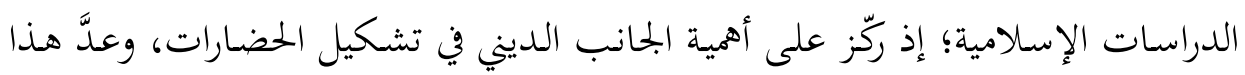
الجانب العنصر الجوهري في تكوينها، وهي فرضية أساسية في تحليلاته للحضارة. وقد ركّز الفاروقي في دراسته على علاقة الإسلام بكل من اليهودية والمسيحية، والتلاقي بين هذه

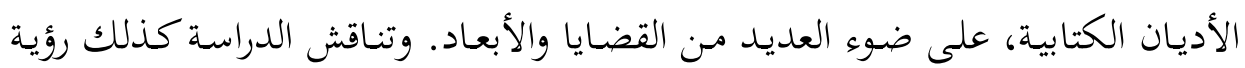
' هنتغتون، صموئيل. صـدام الحضارات: إعادة صنع النظام العالمي، ترجمة: طلعت الشايب، القاهرة: سطور،

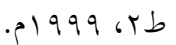

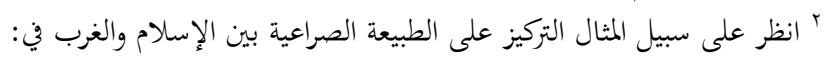

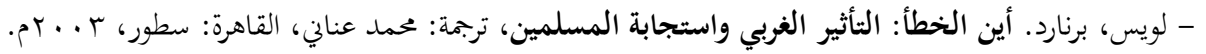

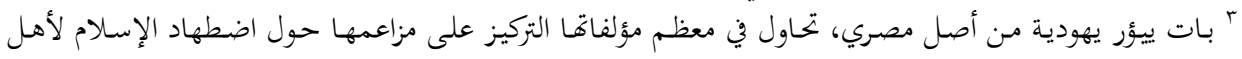
الذمة، انظر: التئر

- Bat Ye'or, "Dhimmitude: Jews and Christians Under Islam", Midstream, FebruaryMarch 1997, pp 9-12. 
الفـاروقي للدور الذي يمكن أن يقوم بـه الإسـلام -بوصفه نظام سلام عالمياً- في تغيير

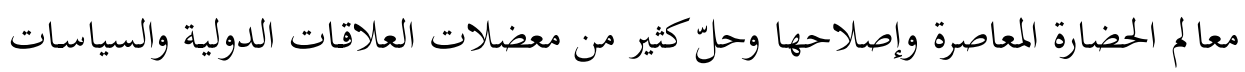
العالمية الراهنة، التي تعاني منها الإنسانية.

\section{أوّالاً: الدور المتوقع للإسلام في تعديل السياسات العالمية}

لم يكتب الفـاروقي بصفة مباشرة ومسهبة حول دور الإسلام في العلاقات الدولية، غير أنَّ العديد من مقالاته المنشورة وغير المنشورة، تركّز على نقد الأوضاع العالمية، ورؤية الإسلام بديلاً للنظام الدولي الحالي، وذلك من منظور معياري قائم على رؤيته التوحيدية، وعلى نظرته لموقف الإسلام من بقية الأديان ومن الإنسانية؛ إذ حاول أن يبرز أخلاقيات

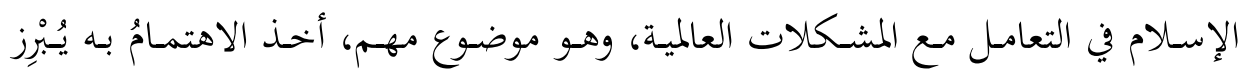
الدعوةً إلى تأسيس نظريات معيارية تعيد الاعتبار للقضايا الأخلاقية التي فم العالم.

\section{1 ـ ضرورة التأسيس لأخلاقيات الإسلام في العلاقات الدولية:}

يرى سهيل هاثمي أن التحليل الوضعي الواقعي يكاد لا ينفصل عن المنظور المعياري

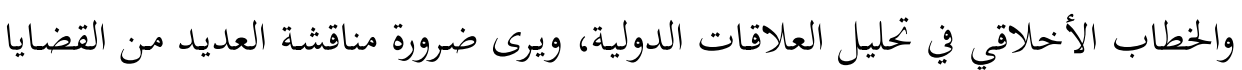

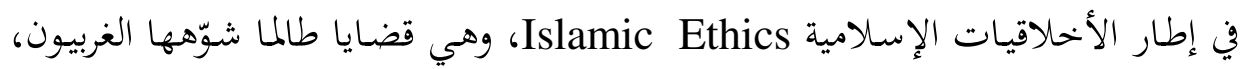
منطلقين في ذلك مس الخلفية العدائية الصليبية بحـاه الإسلام، ومن بينها مفهوم الجهادياد

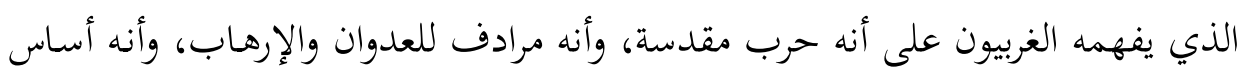

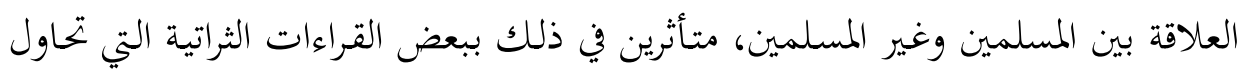

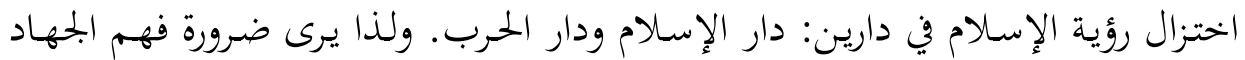

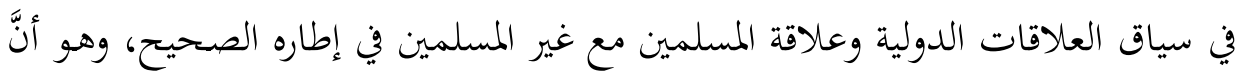

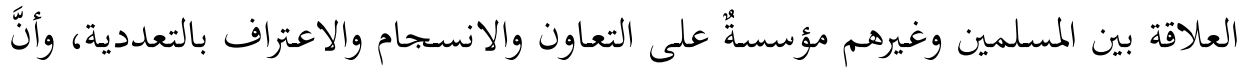

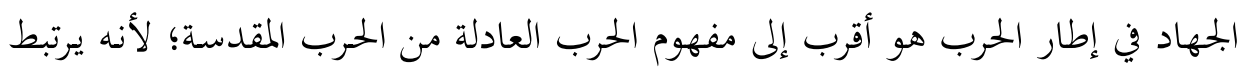
بقيود أخلاقية تمنعه من الانفلات إلى العنف والاعتداء والظلم على الآخرين.

${ }^{4}$ Hashmi, Sohail. "Toward an Islamic Ethics of International Relations: a Research Agend", The American Journal of Islamic Social Science, Vol. 10, No. 01, pp 91-93. 


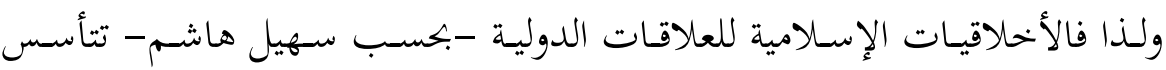

على الأناركية Anarchy وليس على الحرب؛ إذ إن مضموها يتمثل في كوها علاقة مبنية

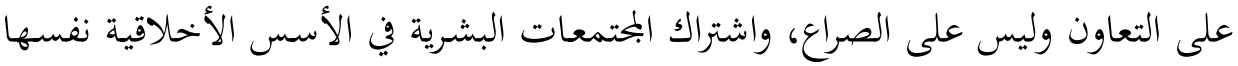

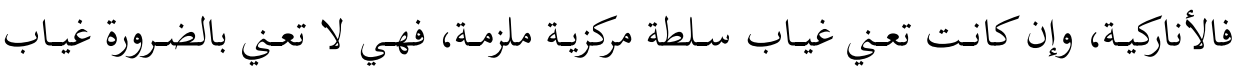
الأخلاق في العلاقات الدولية. وفي إطار النقد الأخلاقي للسياسات الدولية من منظور

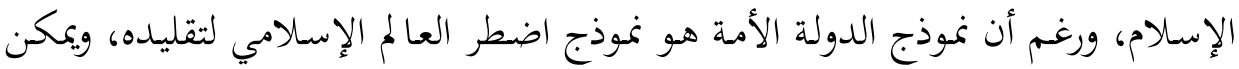

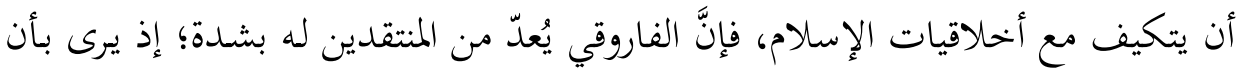

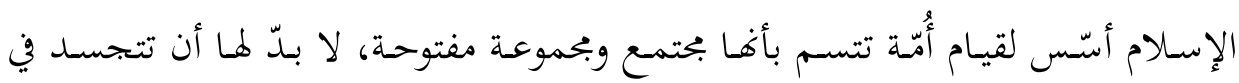

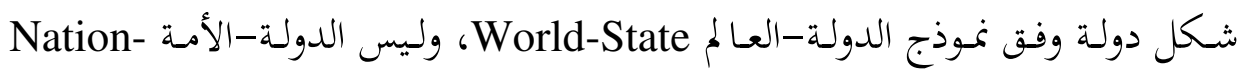
State، وهذه الدولة-العالم ستكون البديل للنظام العالمي الراهن، وإحلال النظام الدولي

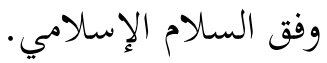

\section{Y. World-State الأُمّة الإسلامية والدولة-العالم}

أما عن الأمة الإسلامية التي تؤسس لدولة العالم بديلاً عن نموذج الدولة-الأمة في

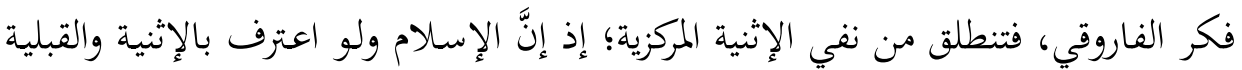

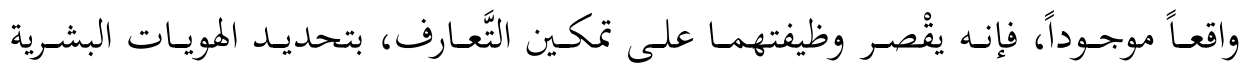

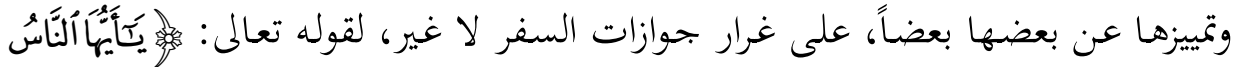

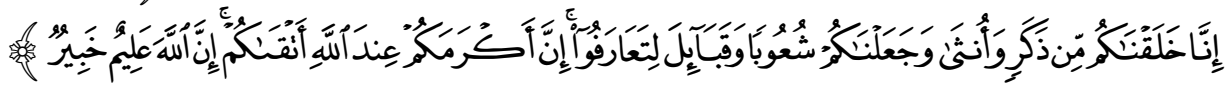

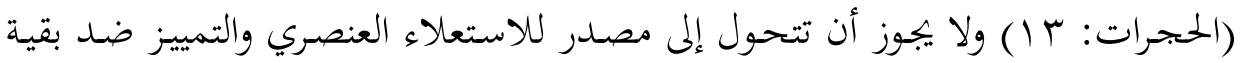

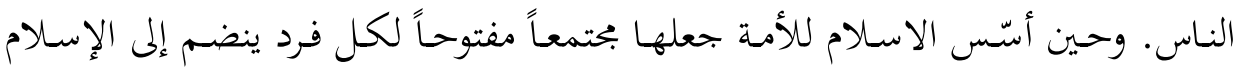

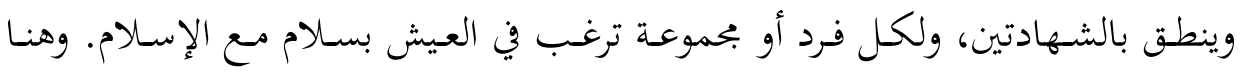

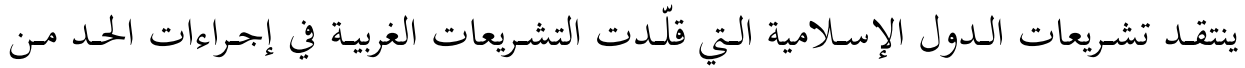

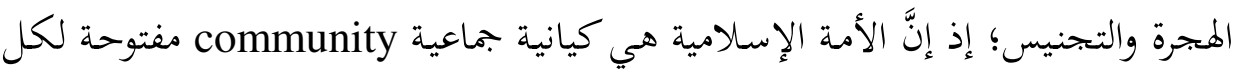

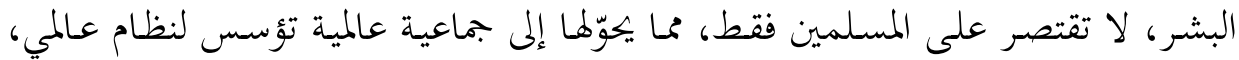
${ }^{5}$ Ibid, p 94. 
يقوم على التعايش بين الشعوب والجماعات البشرية المختلفة.' وفي كتابه التوحيد يرى بأن الأمـة الإسـلامية تقوم في تأسيسها على ثلاثيـة: الرؤيـة، والإرادة، والعملـ؛ فالوحـدة حسب الفاروقي تعني إجماعاً فكرياً وإجماعاً إرادياً وإجماعاً عملياً.

وحول البُعد السياسي في العمل يرى الفـاروقي أنه ينبني على أربعة أركان: الوحدة،

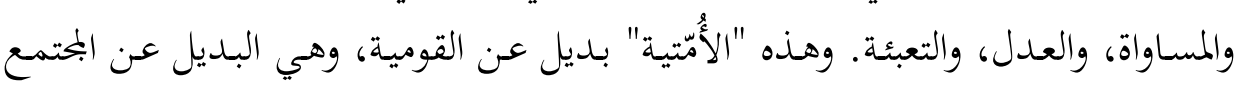
الدولي؛ لأنه يرى بأن الدين، إضافة إلى أنه هو المبدأ المنظم للمجتمع في الإسلام، فهو

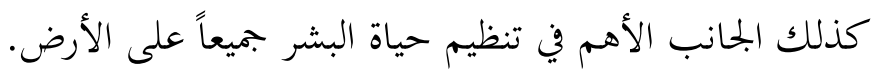

والدولـة الإسـلامية دولـة تعدديـة بطبيعتهـا، يعـترف الإسـلام فيها بأتبـاع الـديانات

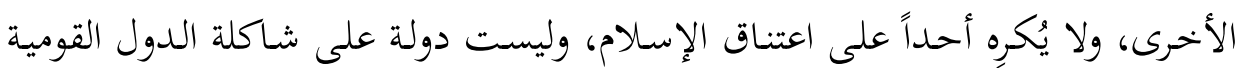

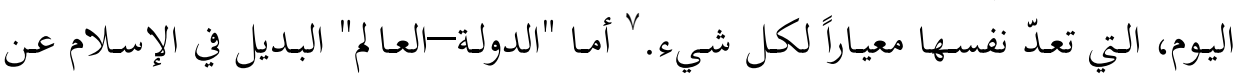
"الدولة-الأمة"، فهي تتضح من خلال مبادئ الشريعة الإسلامية ومن التاريخ الإسلامي؛

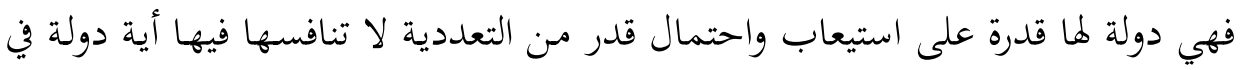

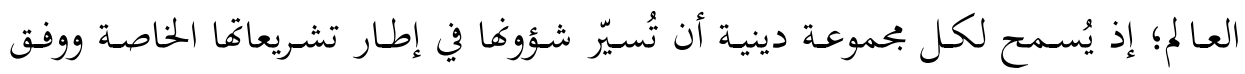

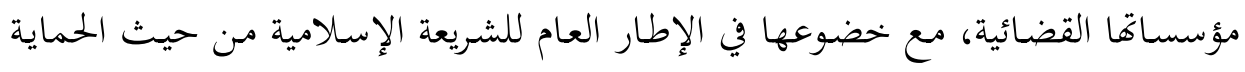

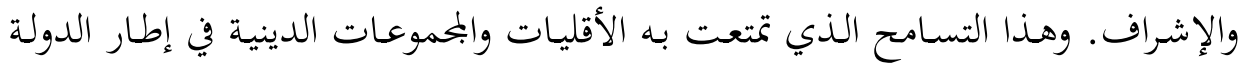

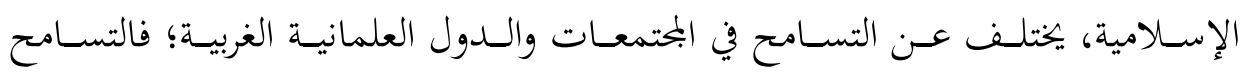

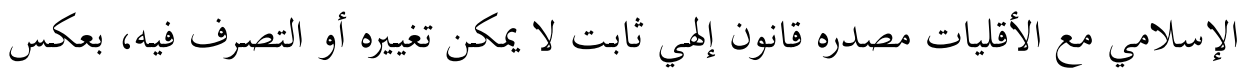

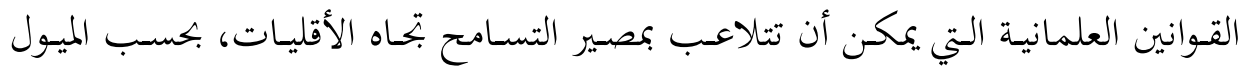

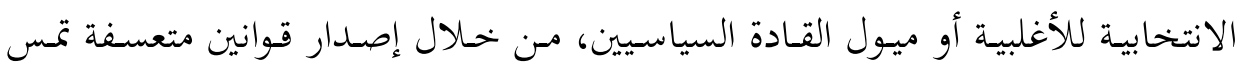

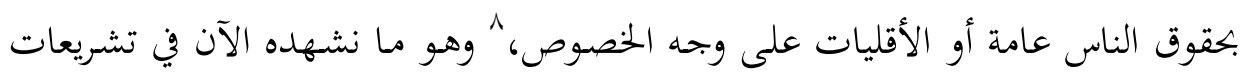

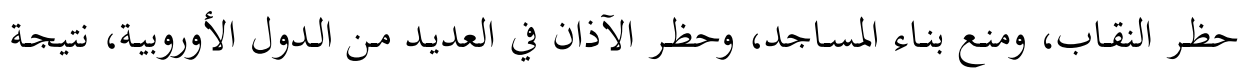

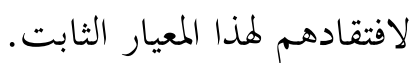

${ }^{6}$ Al-Faruqi, Ismail Raji. "Islam: Movement for World Order", available at: http://www.iiit.org/Research/IsmailalFaruqi/tabid/94/Default.aspx.

ل الفاروقي، إسماعيل راجي. التوحيد: مضامينه على الفكر والحياة، ترجمة: السيد عمر، نسخة إلكترونية، صو • r. ${ }^{8}$ Al-Faruq, Ismail Raji. "Islam: Movement for World Order", Op.cit. 
كما أن دولة الإسـام، هي دولة لكل مواطنيها بـالتعبير الحسالي السـائد؛ إذ يكون المواطنون متساوين فيها في الحقوق والواجبات، ومتساوين كذلك مساواة كاملة في التمتع

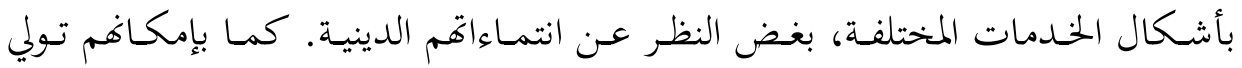

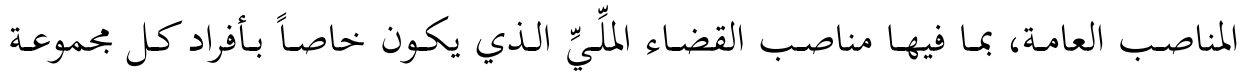
دينية، ويُستنى من ذلك تولي بعض المناصب الحساسة أو التي لما خصوصية معينة، مثل منصب القيادة العليا للجيش ومنصب الخنليفة، فمـن الطبيعي أن يكون مـن صـاحيات

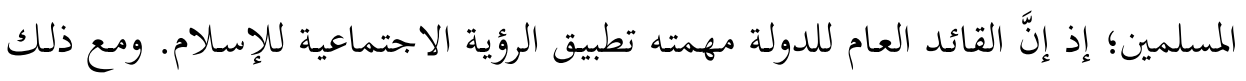

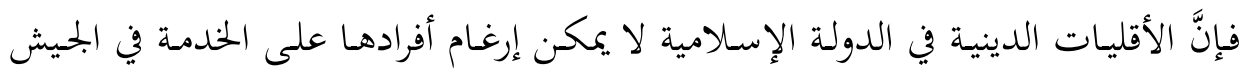

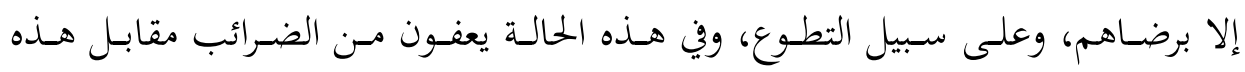

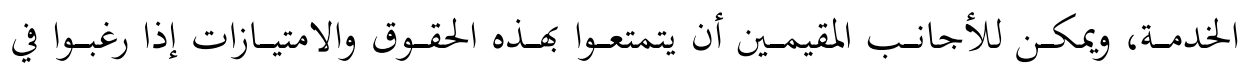
ذلك.

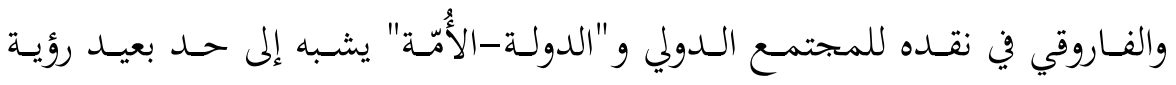
المدرسة النقدية وما بعد الحداثية في العلاقات الدولية؛ إذ يرى الفاروقي أنَّ جوهر المشكلة

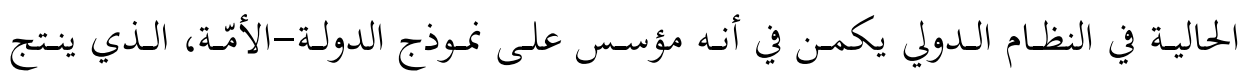

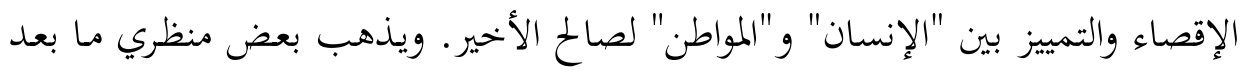

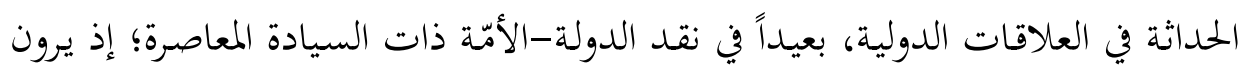
بأها مصدر للعنف الذي يحدث في العالم، بل نشأت الدولة المعاصرة على أساس خطيئة أصلية هي الحرب والعنف. فيرى برادلي كلين Bradley S. Klein بأنَّ الدولة استعملت

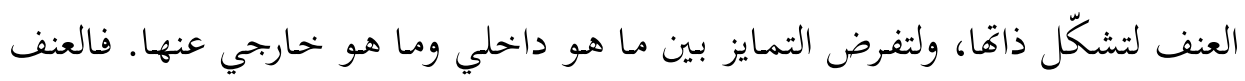

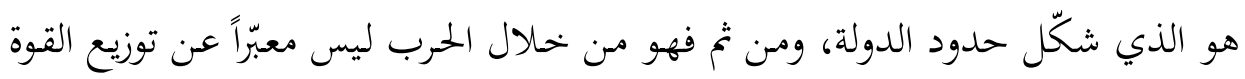

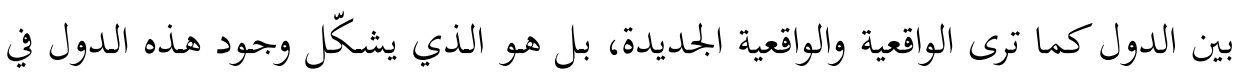
حد ذاتا.

${ }^{9}$ Ibid.

10 Bradley S. Klein, Strategic Studies and World Order: The Global Politics of Deterrence, Cambridge: Cambridge University Press, 1994, p 38. See also: Richard 
أمـا الفـاروقي فيرى بأن الدولة حسين تقوم على الإثنية المركزية في شكلها القومي أو القَبَلي أو أي شكل آخر، فهي تؤسس للظلم وترى نفسها معياراً لكل شيء، فالدول المعاصرة لا سيما الغربية، قامت في جوهرها - ومنذ ظهورها- على الصراع بسبب النظرة الاستعلائية الكامنة في الإثنية المركزية، وصراع الطبقات، وهنا يحدث التصادم بين الدول، ولذا يرى الفاروقي أنَّه لكي يتخلص العالمُ من المآسي التي يعيشها في ظل النظام الدولي

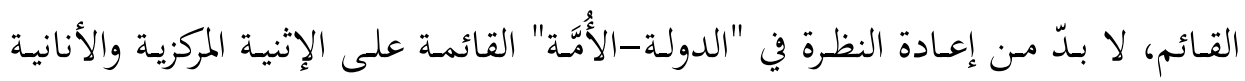
القوميـة والطمـع والتوسـع. وهي بـاعتراف المدرسـة الواقعيـة في العلاقـات الدوليـة، تمثـل الخصائص الكامنة في الدول ذات السيادة في العـالم المعاصر، وتحـدد سلوكيتها الدوليـة. وي خطاب ولغـة تشبه تعبيرات الابجاه مـا بعـد الحمداثي في العلاقات الدولية، والقائمـة على مشروع التنوير والانعتاق بالنسبة للبشرية، يرى الفاروقي بأنه لا بدّ للإنسان من أن يتحرر مـن طغيان هذه النظرة الاستعلائية، والممارسة الاختزالية، والإقصاء الذي تمارسه الدول المعاصرة.

\section{ثانياً: النظام الدولي والسالام الإسلامي}

في هذا الإطار يرى الفاروقي ومن منظور معياري أن الإسلام أسّس ويؤسس لنظام

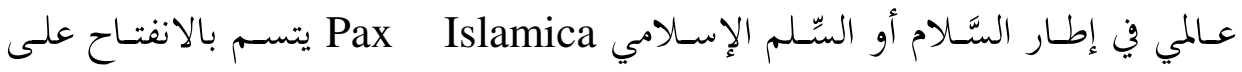
الجماعات والأفراد من مختلف الأجناس والأديان، على أساس الحوار والإقناع والاقتناع، بدلاً من فرض الأمر الواقع والقوة والإكراه، كما يحدث في النظام الدولي الراهن الغالب، ومنح حرية الحركة والتنقل عبر الحـدود للأفكار والبضائع والأفراد. وينتقـد النظام الدولي تركي والسياسة الدولية القائمة على تنظيم الأمـم المتحدة. إن الفاروقي يرى في هذا النوع مـن

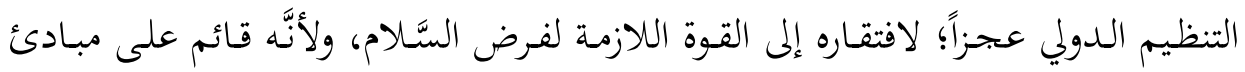

Devetak, "Postmodernism", in: Scott Burchill et all, Theories of International Relations, London: Palgrave Macmillan, 2005, p 173.

${ }^{11}$ Ibid. 
متناقضة، تتمثل في مبدأ السيادة للدولة الأمَّة، وسيطرة القوى العظمى على السياسات

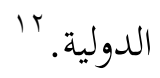

ويرى الفـاروقي بأنه ينبغي أن يكون للدين دور في تشكيل ملامح المختمع الدولي،

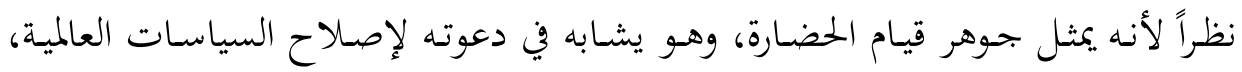

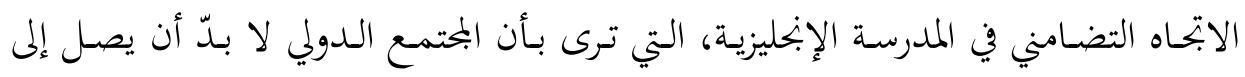

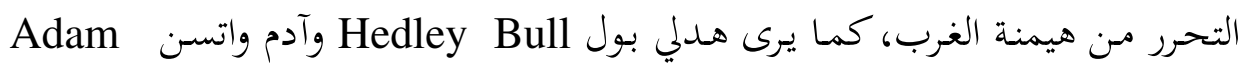
Watson

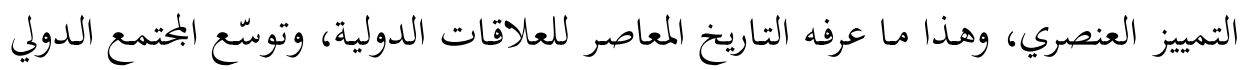

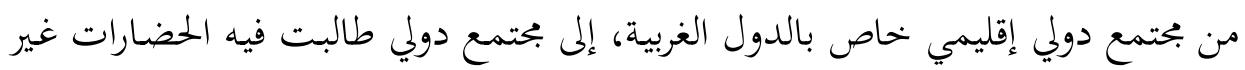

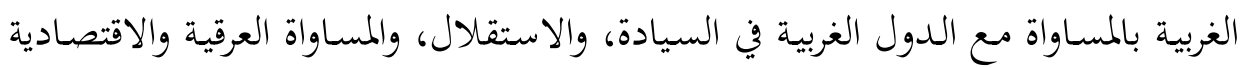

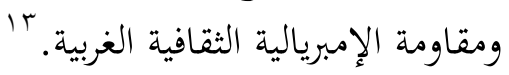

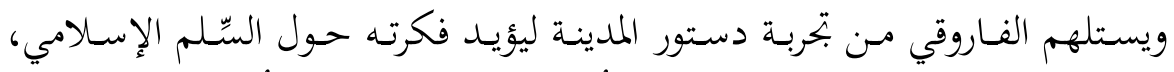

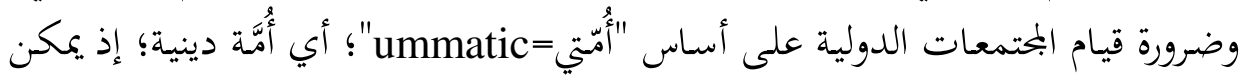

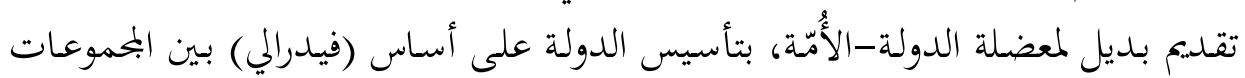

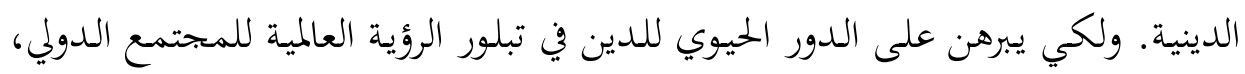

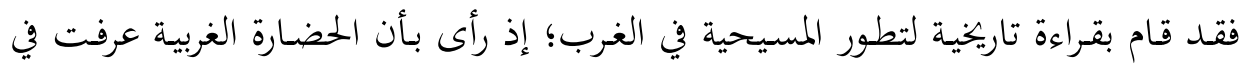

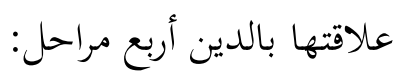

- في المرحلة الأولى جاءت المسيحية في البداية ديانة عالمية، ثم تحولت من مسيحية يهودية توحيدية، إلى مسيحية رومانية وثنية، أجهضت التوجُّة العالمي الأصلي فيها. - والمرحلة الثانية تمثلـت في ظهور حركة التنوير الغربية، التي كان مـ انعكاساتها

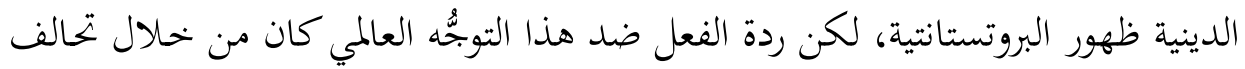
r' الفـاروقي، إسماعيل راجي. أطلس الحضـارة الإسـلامية، ترجمة: عبد الواحد لؤلؤة، الرياض: مكتبة العبيكان،

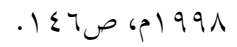

${ }^{13}$ Andrew Linklater, "The English School" in: Scott Burchill et al, Theories of International Relations, pp 84-109, $3^{\text {rd }}$ edition, New York: Palgrave Macmillan, 2005, p.100. 
المسيحية والملوكك ضد حركة التنوير، بظهور حركتين مضادتين: الرومانسية المسيحية ضد العقلانية التنويرية، والقومية الخصوصية ضد العالمية التنويرية، لكن انتشار الفكر التنويري أدّى بدوره إلى تبلور نقد عنيف، كان من تمثّلاته الرفض الجلذري للدين، فتمّ انتقاد الدين على مستوى وظيفتـه الاجتماعيـة والسياسية في كتابـات مـاركس وإبخلز، وتطور مفهوم "الدين أفيون الشعوب"، وانتُقد الدين في أبعاده الفردية على المستوى الأخلاقي والنفسي من خلال كتابات نيتشه وفرويد.

- - المرحلة الثالثة: تبلورت في منتصف القرن التاسع عشر حركات اشتراكية وشيوعية

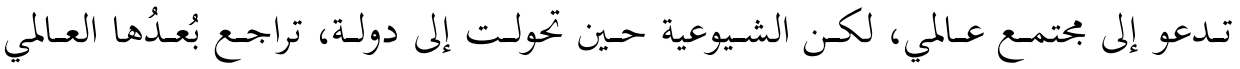

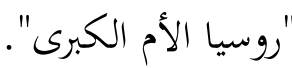

- ــ وأمـا المرحلة الرابعة فتتمثل في رأي الفـاروقي في التوجـه العـالمي الذي برزت فيـه

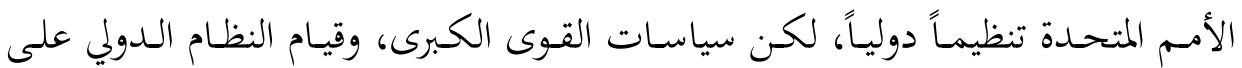
أسس الدولة القومية، وسلوك الدول على أساس المصلحة القومية جعل هذه المنظمة غير

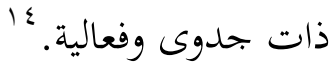

ويرى الفاروقي بأن فشل النظام الدولي الحالي في ضمان السلام والعدالة والاستقرار، يعود إلى الجوهر الحضاري الذي تقوم عليه السياسة الدولية، والمبادئ التي تحكم العلاقات الدوليـة؛ فالمسـيحية مـن خهلال فصـلها بـين الـدين والكنيسـة، أفسـحت المحسال لإخهاء الممارسـة السياسـية مـن أي التـزام أخلاقي، وإعـلاء القوميـة والتمركز الإثـني على كـل الاعتبارات الأخلاقية الإنسانية، كما أن ذلك أدى إلى فقر فكري للقانون الدولي الغربي، الذي تبلور فقط مـن خلال المعاهـات والاتفاقات بين الدول، لكـن هذه الاتفاقات لم يكن يتم احترامها من قبل القوى الغربية حين يتعلق مع دول غير غربية، التي يراها الغرب أقل شأنًاً منه.

${ }^{14}$ al Faruqi, Ismail Raji. "Introduction", in: AbuSulayman, AbdulHamid A. Toward an Islamic Theory of International Relations: New Directions for methodology and Thought, $2^{\text {nd }}$ ed, Virginia: The International Institute of Islamic Thought, 1993. 
ولذلك يرى الفـاروقي بأن النظام العالمي الذي يـدعو إليه الإسـام، ينبغي أن يقوم

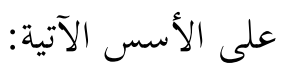

أ. الحرية: وذلك بدلاً من استعباد الناس لبعضهم بعضاً، فالإسلام حرّم الاستعباد بكل طرقه باستثناء حالة أسرى الحرب، ومع ذلك فقد حضّ على تحريرهم. ويتضمن هذا

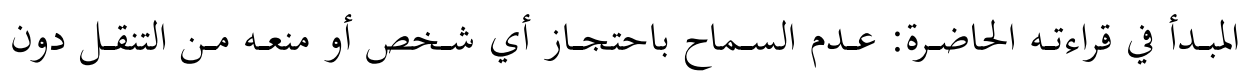

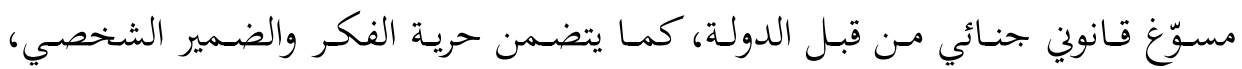

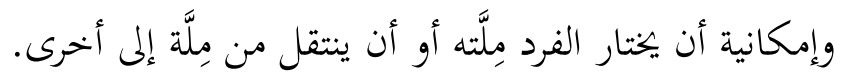

ب. الانفتاح: يرى الفاروقي أن الله سخر الأرض للإنسان، وبناء على ذلك فإنه لا

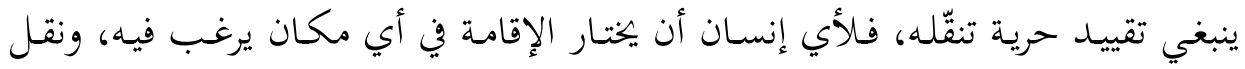

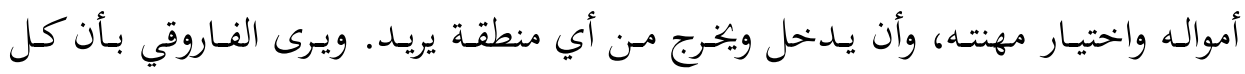

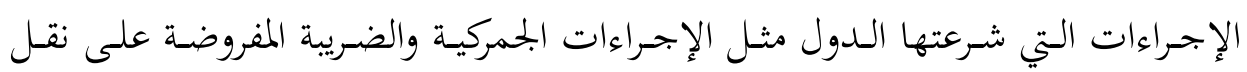

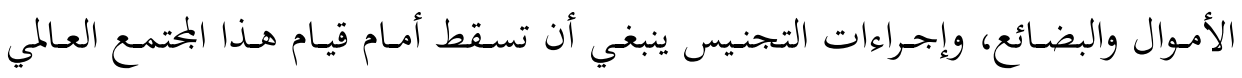
المفتوح.

ج. المساواتية: ويعني بذلك تساوي البشر أمام القانون، وتساويهم في فرص التعليم

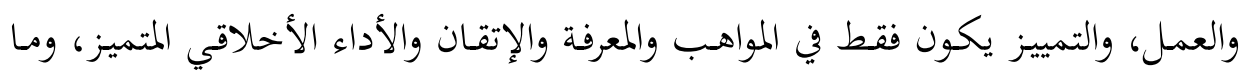

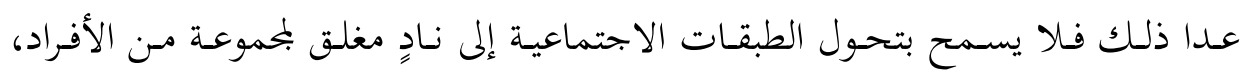
وإدانة ومحاربة كل تنظيم أو كيان قائم على الفصل العنصري. د. العالميـة: ويقصـد بـذلك التـذكير بالمبـدأ الإسـلامي الذي يـرى أنَّ البشـرية كلهـا

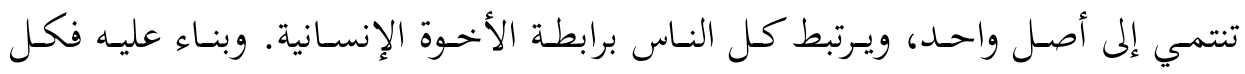

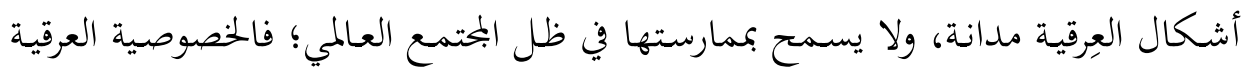

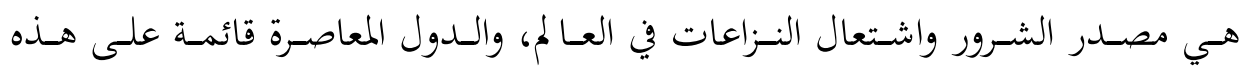

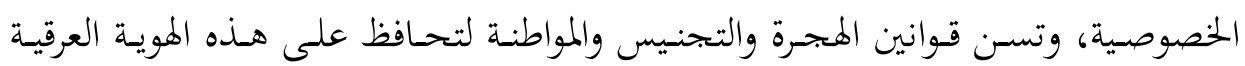


هـ العدالة: يرى الفاروقي بأنَّ القانون الدولي الإسلامي يضمن العدالة لكل البشر،

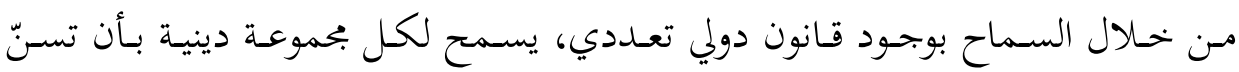
قوانينها وتتحاكم إليها في إطار الأحوال الشخصية والشؤون المِلِّيّة، مع إشراف القانون

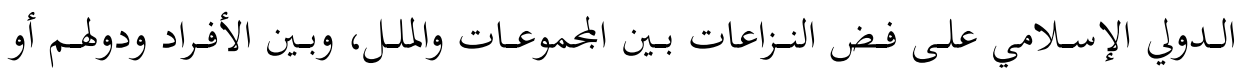
مللهم.

و. حريـة الإقنـاع والاقتنـاع: وهـو مـن المبـادئ الأساسية التي بتعـل المجتمع البشـري يتخلص من الوصاية الفكرية والدينية، التي قد يمارسها بعض رجال الدين على الآخرين، وتمكّن الإنسان من أن يختار مِلّته وأسلوب حين حياته.

وبناء على ذلك يمكن أن نستخلص منظور الفاروقي للعلاقات الدولية على أساس: بنـاء نظام عـالمي على أسـاس السّالام الإسـامي المنفتح على الأمـم والأفراد والجماعـات الذين يؤمنون بمبدأ الإقناع والاقتناع. وهذا النظام بنحد جذوره التطبيقية الأولى في دستور

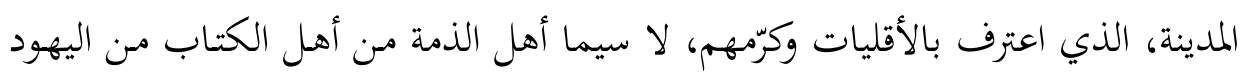
والنصارى. وهـا النظام العالمي القـائم على السّـلام الإسـلامي، هو الذي عرفته التجربة

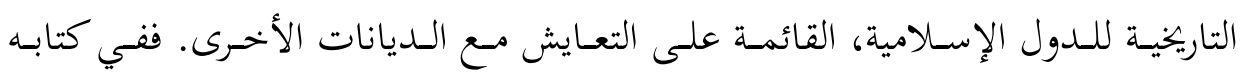

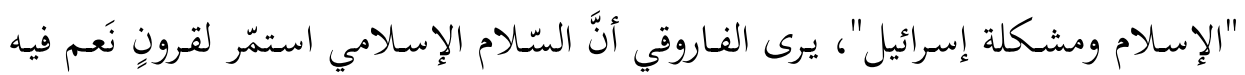
اليهود بالحرية والازدهار والتسامح. ولأنّ هذا التسامح من مصدر إلهي غير قابل للتبديل، فإنه يتفوق على النظام الغربي الحالي. أمـا التسامح المسيحي بتحاه اليهود في الغرب، فلم ينشأ إلا عندما فقد الغربيون تدينهم بالمسيحية، بل يرد الفاروقي على من يزعم بازدهار

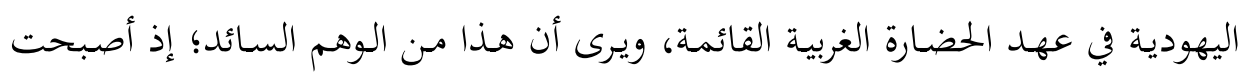
الديانة اليهودية ألعوبة بين أيدي الصهيونية والقوى العلمانية الغربية، وحتى إبحازات اليهود في هذا العصر، تمت على حساب اليهودية؛ لأن إبحازاتم غير يهودية، على الرغم مـن أها صدرت من أفراد يهود (ماركس، فرويد، إلخ).

${ }^{15}$ Al-Faruqi, Ismail Raji. Islam and the Problem of Israel, 4th ed, Selangor, Malaysia: The Other Press SDN Bhd, 2006, p 91. 
وهـذا السّـلام الإسـلامي لا يمكـن ضـمانه إلا بوجـود حريسة للحركة، تشـمل حركـة البضـائع والأشـحاص والثتروات مـن دون قيـد، وهـــه المبـادئ المتعلقـة ببنـاء نظـام سـلام عالمي، مثّلت أهم الإشكالات النظرية والتفسيرية والمعيارية، في حوارات العلاقات الدولية بـين الواقعيـة والمثاليـة، وبـين الواقعيـات الجمديـدة والليبراليـات الجلديـدة، ونظريـات مـا بعـد الوضعية، من حيث أهمية القيم في العلاقات الدولية، وقيم الحوار، والعدالة، والديمقراطية،

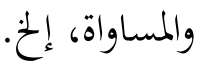

وينتقـد الفـاروقي دور الدولة ونمط السيادة وفق صسيغها المعاصـرة القائمسة على مبـدأ

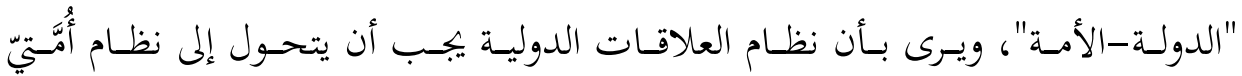
Ummatic بدلاً من نظام الدولة القومية؛ إذ يصبح بإمكان أي بحموعة دينية أن تنتظم

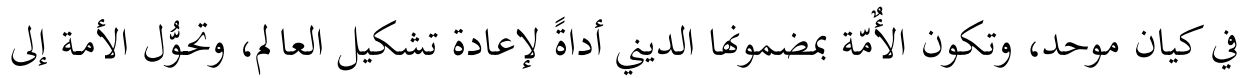

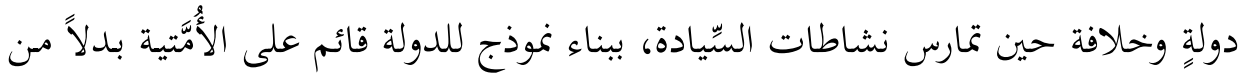

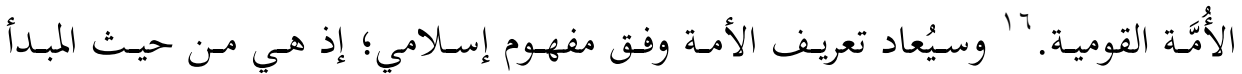

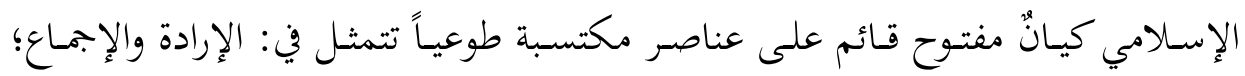
إجماع الرؤية، وإجماع العمل، وإجماع الإرادة، وليس قائماً على الانتماء اللغوي أو العرقي

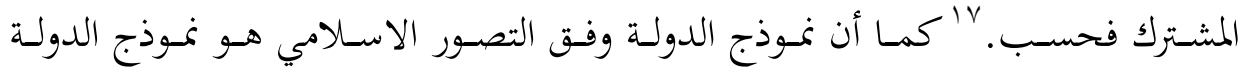

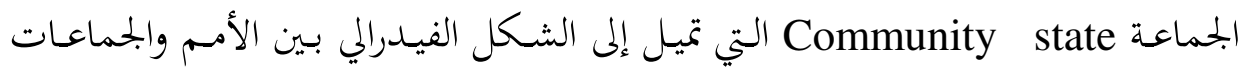
الدينية. وهذه الفيدرالية الإسلامية تختلف عن الفيدراليات الحاضرة من ناحيتين: الناحية

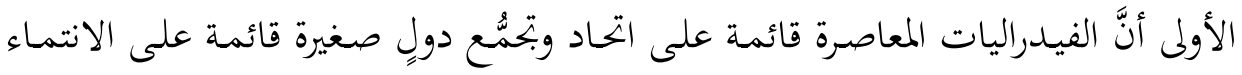

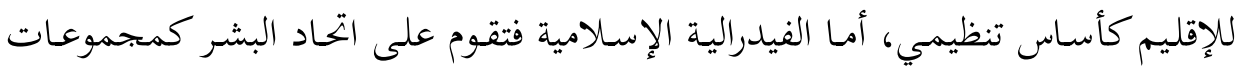

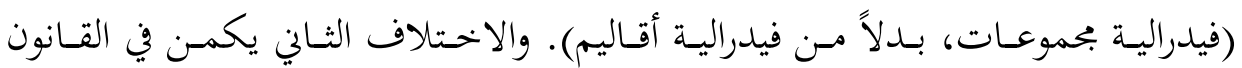
الفيدرالي الذي ينظمها، وهـا القانون قائم على الأغلبية في الفيدراليات الغربية، أمـا في

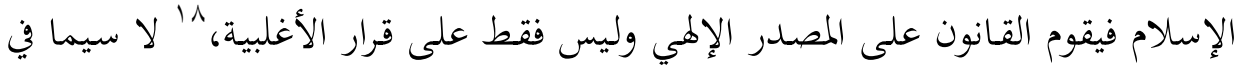

${ }^{16}$ Al-Faruqi, Ismail Raji. AL Tawhid: Its implications for thought and Life, Virginia: The International Institute of Islamic Thought, 1992, p 142.

${ }^{17}$ Ibid, p 143-45.

${ }^{18}$ Al-Faruqi, Islam and the Problem of Israel, Op.cit, p 112. 
المضامين والنصوص القطعية، مثل تلك المتعلقة بالحقوق الممنوحة لغير المسلمين من أهل الذمة، وهي حقوق غير قابلة للتصويت أو أن يتصرف فيها قانون الأغلبية.

وضرورة البحث والتفكير في إعادة صياغة نظام للأمم المتحدة، أو التنظيم العالمي، يتجاوز الخلل الموجود في الأمم المتحدة الحالية، فهذا النوع من التنظيم يفتقر إلى الآليات

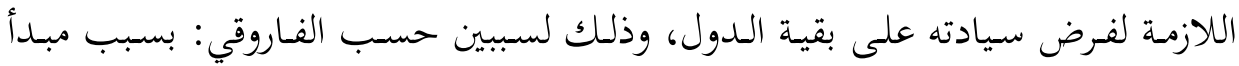

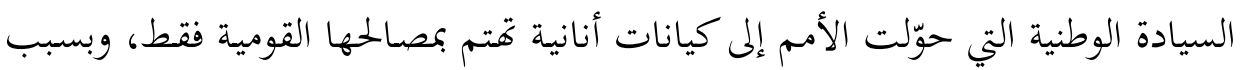

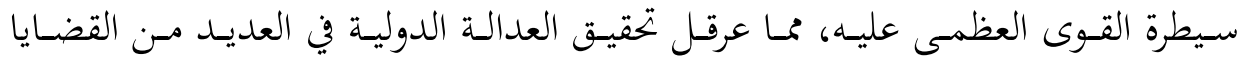

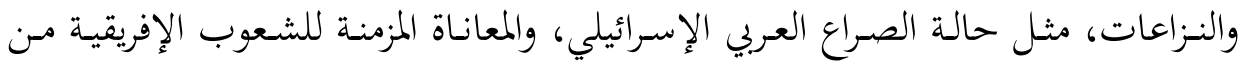

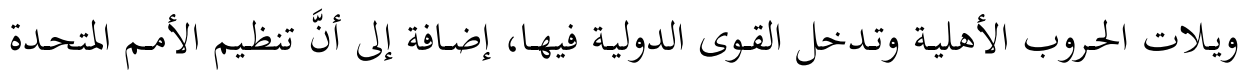

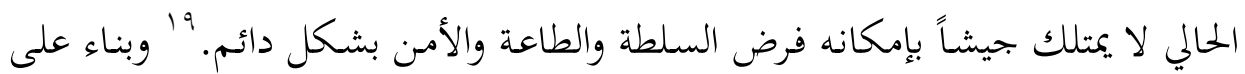

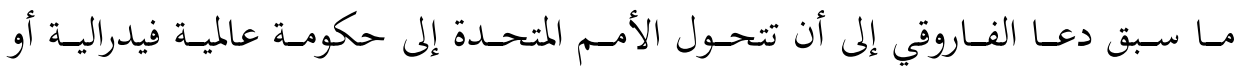

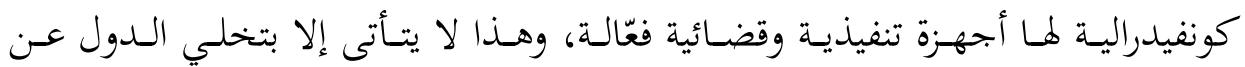

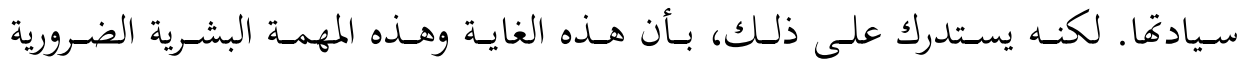

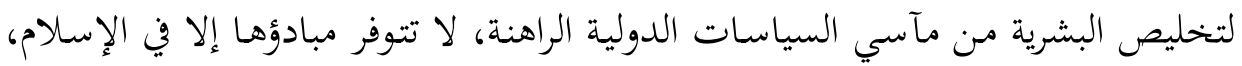

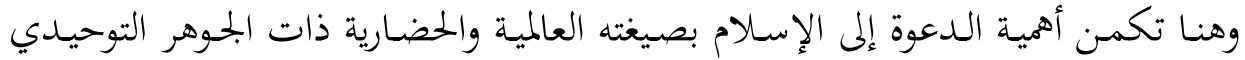
حسب الفـاروقي، وبغير ذلك فالتشريعات والقـوانين التي تسن على مستوى التنظيمات الدولية، خاصة الأمم المتحدة، ستبقى حبراً على ورق، على غرار الإعلان العالمي لحقوق الإنسان. r.

\section{ثالثاً: ملحوظات نقدية على قراءة الفاروقي لدور الاسلام في العلاقات الدولية} وبحسـب هـذه القـراءة الخناصـة بنظـرة الفـاروقي لـدور الاسـلام في العلاقـات الدوليـة القائمة على نظام السلام الإسلامي، يمكن أن نبني عليها ملحوظات تتصل بقراءة الواقع وبتأويل تعاليم الإسلام والتجربة التاريخية للمسلمين. وبتحيء هذه الملحوظات بعد مرور

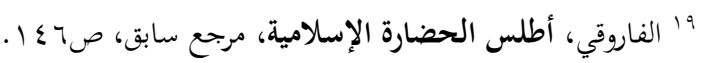
${ }^{20}$ Ismail Raji al-Faruqi, "Introduction", in: AbuSulayman, AbdulHamid A. Toward an Islamic Theory of International Relations, Op.cit, $\mathrm{p} 36$. 


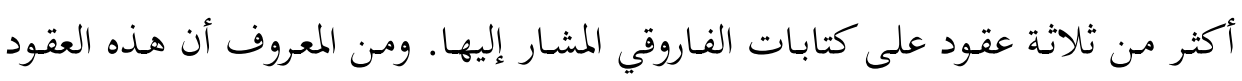

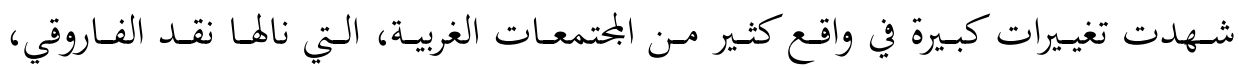

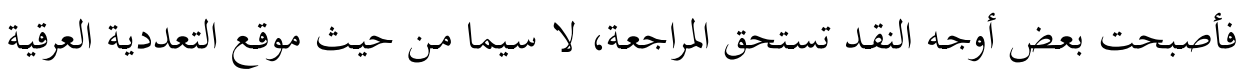

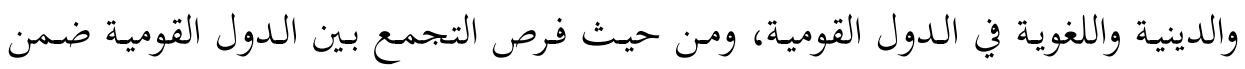

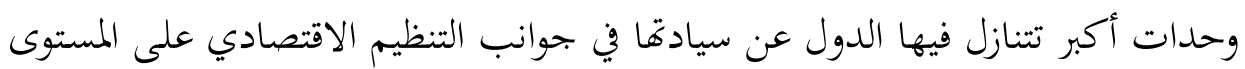
الإقليمي والدولي.

الملحوظة الأولى أنّ نقد الفاروقي للمجتمع الدولي وتقديمه للتصور الإسلامي حول

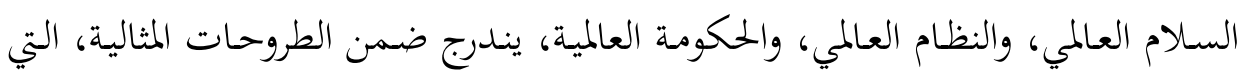

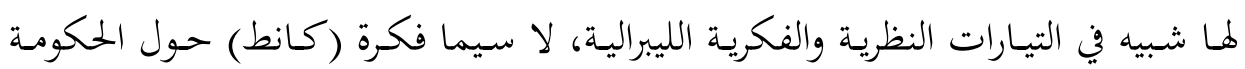

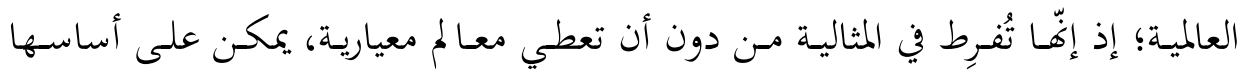

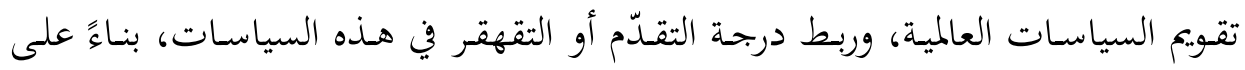
المعايير المرسومة التي ينبغي أن تكون لها صلة بالواقع.

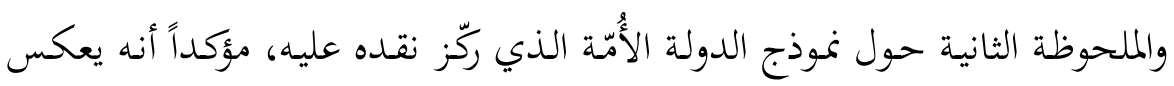

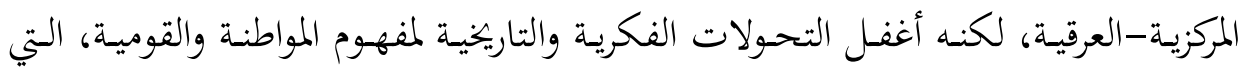

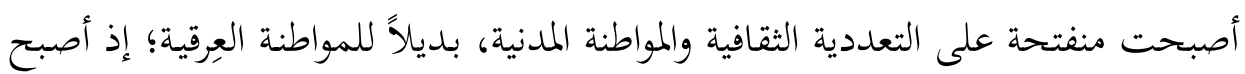

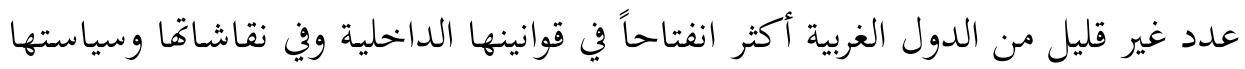
تجاه المهاجرين من فترات سابقة.

كما أن النظام الإسلامي الدولي الذي لا يعترف بالكيانات الجماعية سوى المِلية

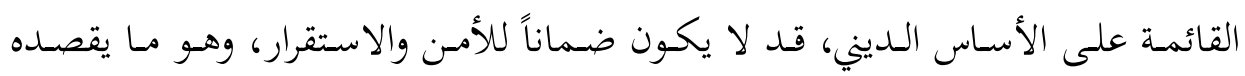

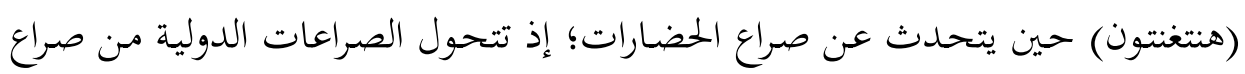

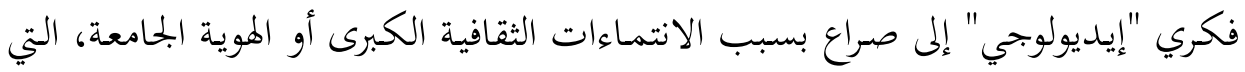

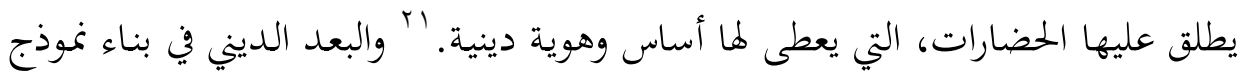

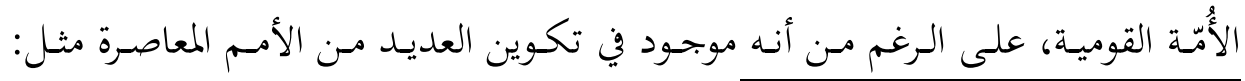

${ }^{21}$ Samuel P. Huntington, "The Clash of Civilization", Foreign Affairs, Vol. 72, No. 3, Summer 1993, p 23-24. 


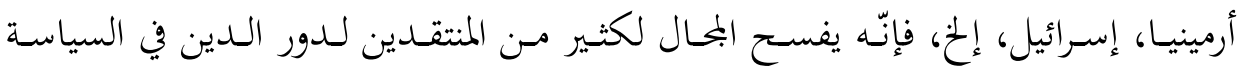

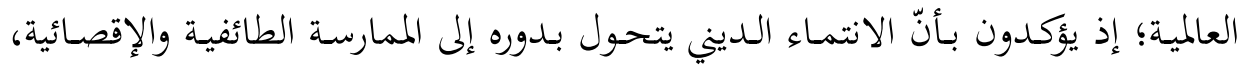

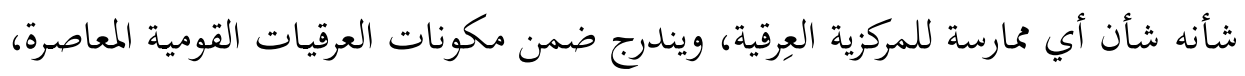

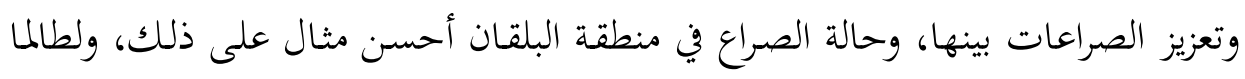

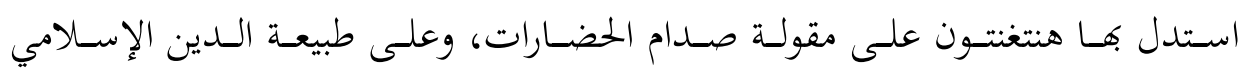
الصدامية والمعادية للغرب، وطبيعة حدوده الدموية.

لكن آراء الفاروقي تخالف منظور صراع الحضارات عند هنتنغتون؛ إذ تؤكد على دور

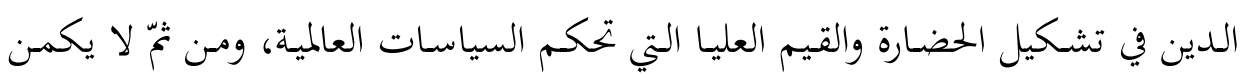

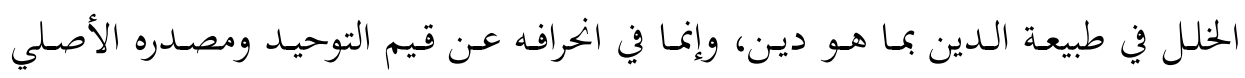

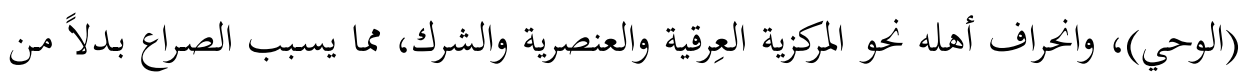
التعاون والانفتاح على المجتمعات المختلفة. وبالنسبة لفكرته عن الأُمتّية، فإنّ المشكلة تكمن في طريقة تحقيق هذا التحوّل من فئن

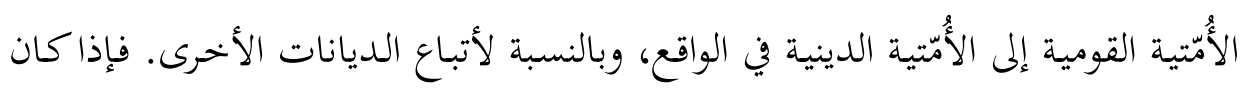

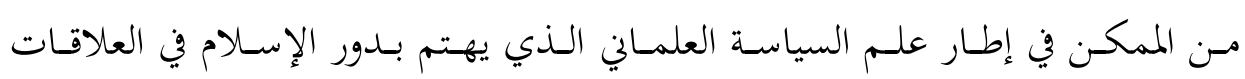

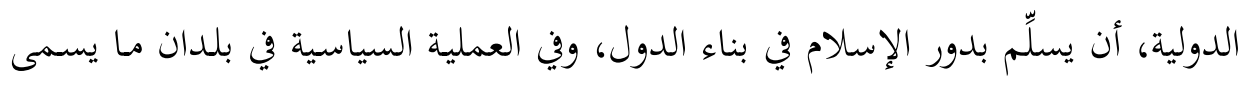

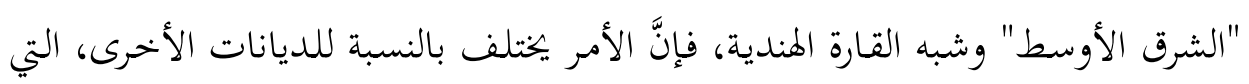

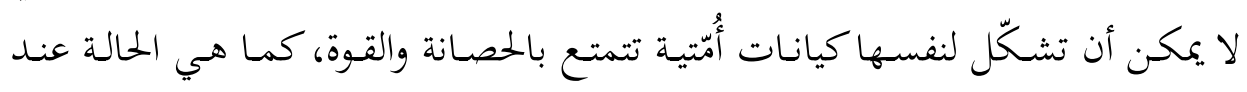

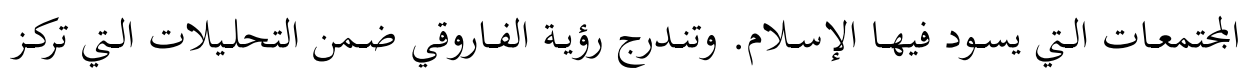

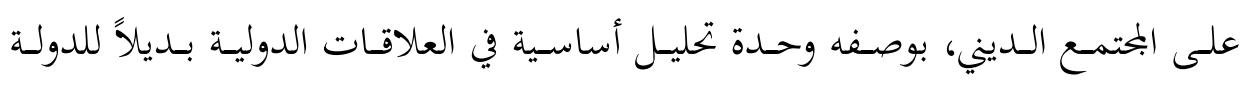

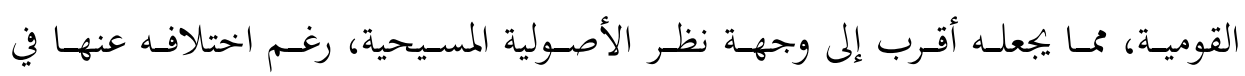
المنطلقات والنتائح.

${ }^{22}$ Ibid, p 33-34.

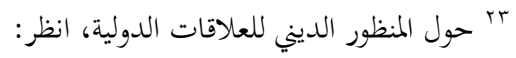

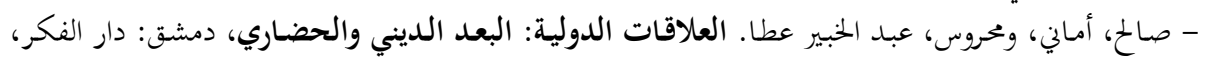
$.101-10.0$. 101 
كمـا أن نظرة الفـاروقي للدولـة الإسـلامية مـن الــاخل تحتـاج إلى المزيـــ مـن الدقـة

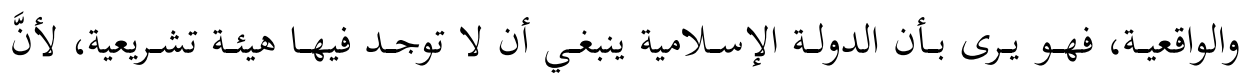

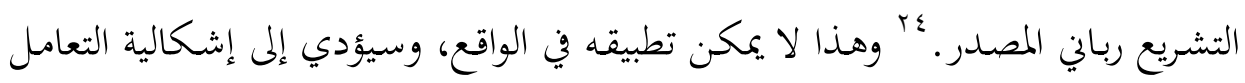

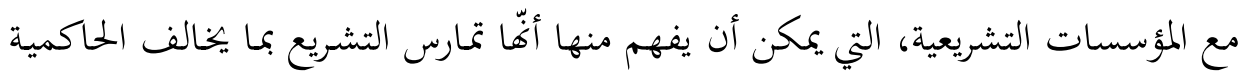

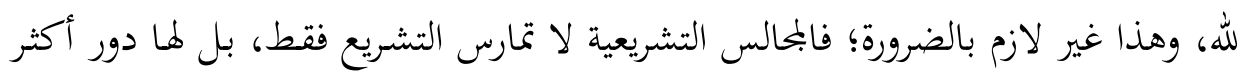

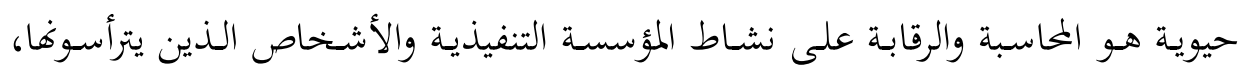

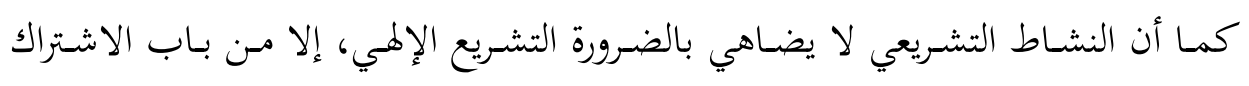

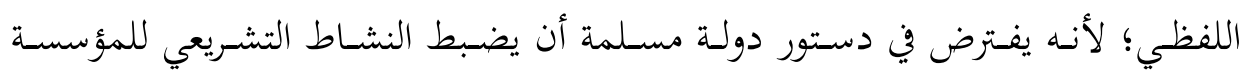

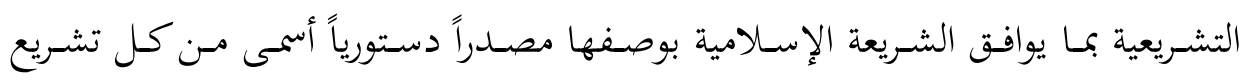

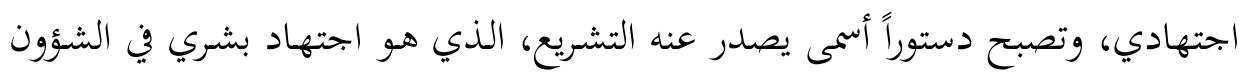
العامة؛ إذ كل تشريع يخالف الشريعة يُعدّ غير دستوري.

وفي إطـار النظام الدستوري، لا بـدّ لكل مؤسسـة أن تمـارس نشـاطها ضـمن حسدود

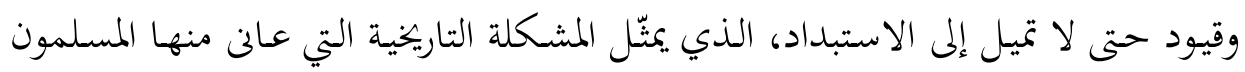

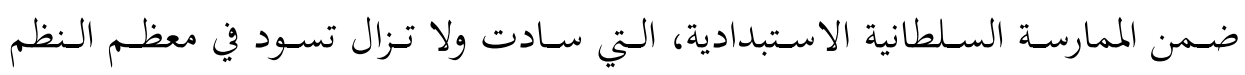
السياسـية في العـا لم الإسـلامي. ومـن الناحيـة التاريخيـة مـورس التشـريع في صـورة اجتهاد

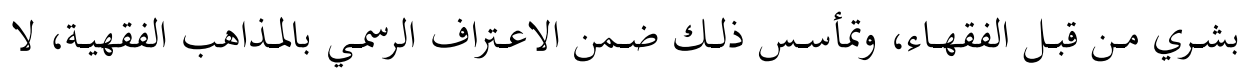
سيما المذاهب السنية الأربعة؛ إذ أصبح النشاط القضائي، خاصة في الأحوال الشخصية

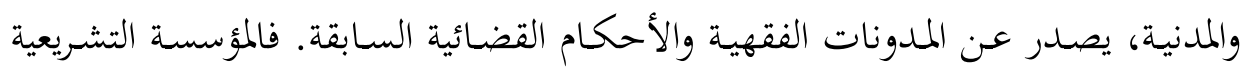
عنصر مهم في توازن السلطات من الناحية القانونية الدستورية، والتخفيف من الاستبداد،

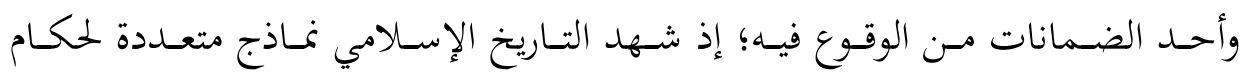
مستبدين ضربوا بربانية التشريع والشريعة عرض الحائط، وانحرف كثير منهم إلى استغلال التعـاليم الإسـلامية وفق صسياغة مذهبيـة تحريفية، كرَّست لأشكال مـن الحكىم السـلطاني

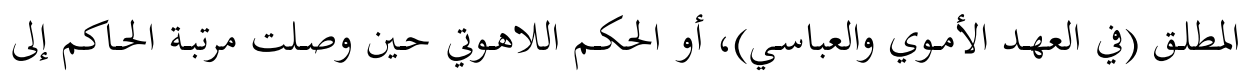
العصمة كما شهدةا تجربة الخلفاء الفاطميين.

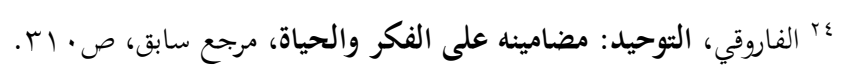


إنّ تصـور الفـاروقي حـول البـديل المتعلـق بالسّـلام الإسـلامي، بخضـوع الجماعـات

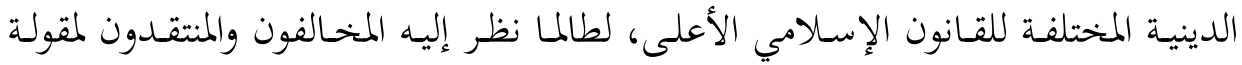

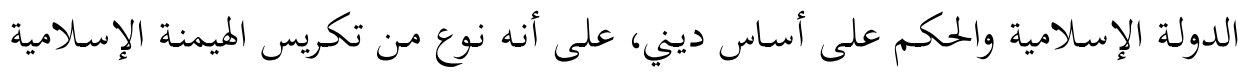
عـن طريـق الجهاد والإكـراه المباشـر وغـير المباشـر على اعتنـاق الاسـلام، وعـودة المركزيـة العرقية-الدينية من النافذة، بعد أن حاول الفاروقي أن يخرجها من الباب. وفي حديثه عن ولن الخلافة الإسلامية لم يوضح طبيعتها وعلاقتها بالدولة الإسلامية وبالأمة الإسلامية؛ لأنه عدّ مصطلح الدولة مفهوماً غربياً، وعدّ الخلافة بحسيداً لسيادة الأمة.

خاتمة:

حدد الفاروقي منهجاً في دراسة الحضارات والأديان، ضمن بحالات إسلامية المعرفة ودراسة الأديان، وركّز على المحدد الديني اليهودي والمسيحي، على أنه الأساس في فهـم إسها

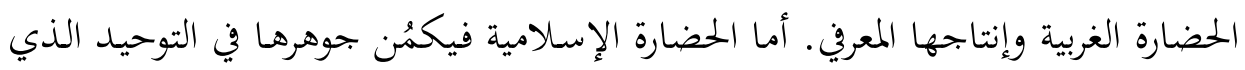

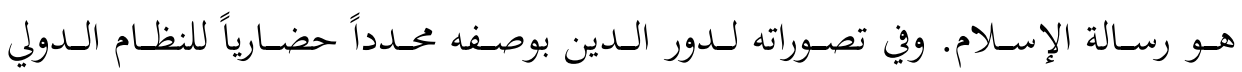
المعاصر، لا يمكن فهم مضمون هذا التصور دون الإلمام بثلاثة عناصر في فكر الفاروقي: العنصر الأول هو إسلامية المعرفة، وهو مشروع وتصور فكري معرفي ينبّه إلى أهمية

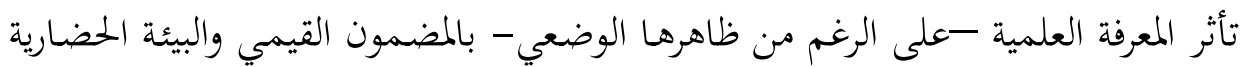
التي تنشأ فيها، مما يحتم ضرورة إنتاج معرفة علمية تستجيب لحاجحات المسلمين في هذا

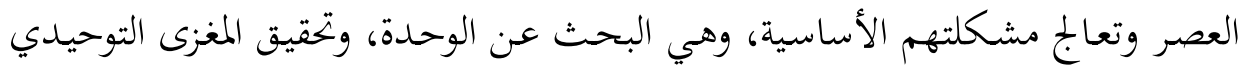
للرسالة الاسلامية، بتوحيد المعرفة، وتوحيد الخالق، ووحدة الحقيقة.

والعنصر الثاني هو المنهجية والتصور النظري والنقدي الذي قدّمهه في إطار الدراسة

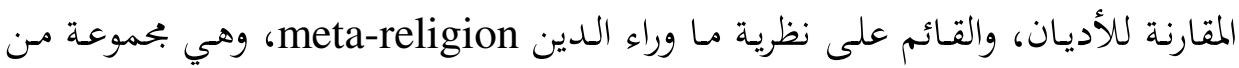

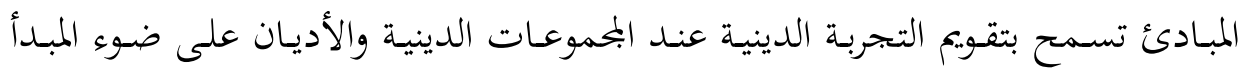

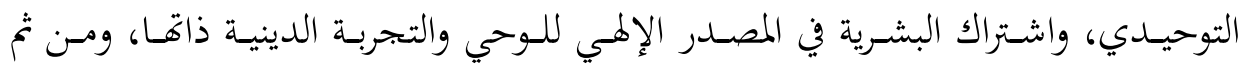

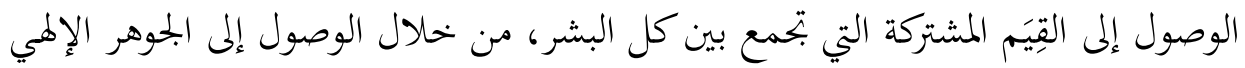

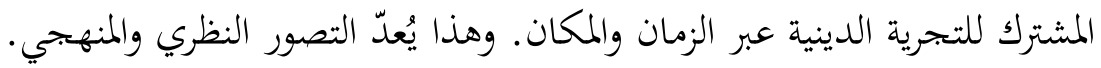


والعنصر الثالث يختص بتقديم نظرية وتصور معياري ونقدي للعلاقات الدولية؛ إذ إذ

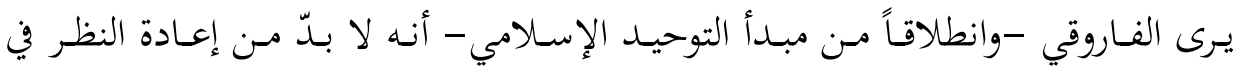

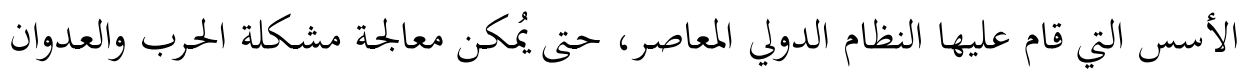

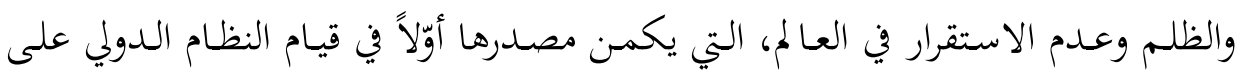

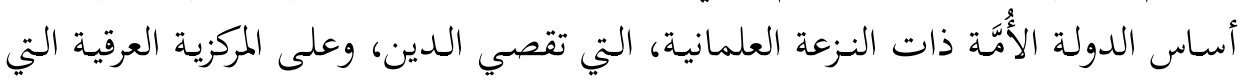

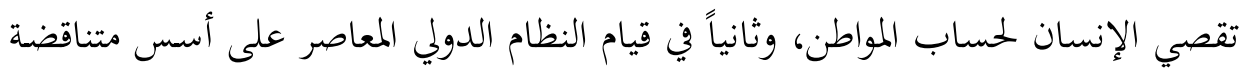

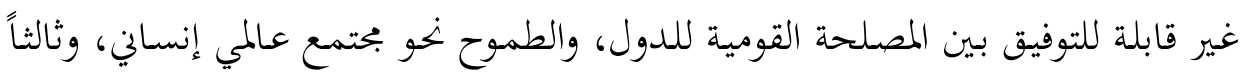

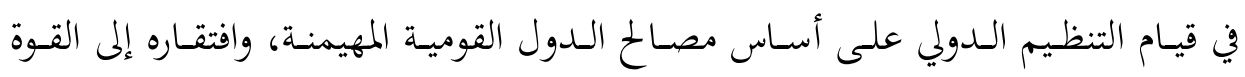
والمؤسسات التي تسمح له بفرض إراداته على الدول القومية.

وقد قدّم الفاروقي تصوراً بديلاً في إطار دراسته لمبادئ الإسلام القائمة على السّلام

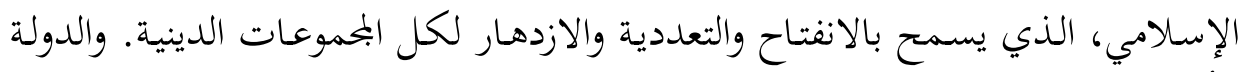

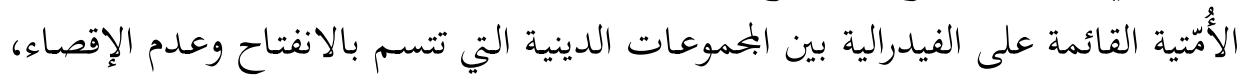

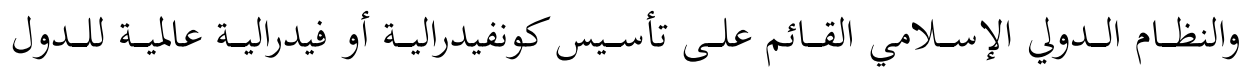
والجماعات، تكرس جهودها لخدمة السّام والإنسانية.

تبقـى بعض المسـائل الـتي تسـتدعي إعـادة التقـويم والنظـر ضـمن المنظـور المعيـاري الإسلامي في العلاقات الدولية حسب تصورات الفاروقي، وتطبيق رؤيته حول إسلامية

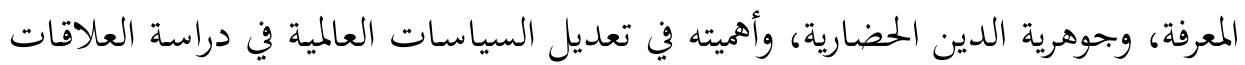

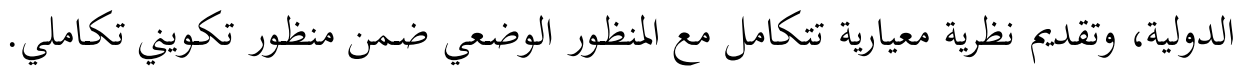

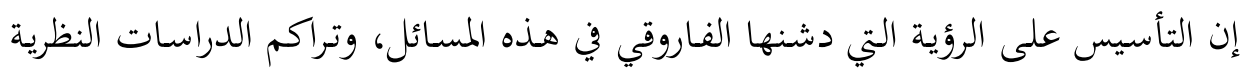

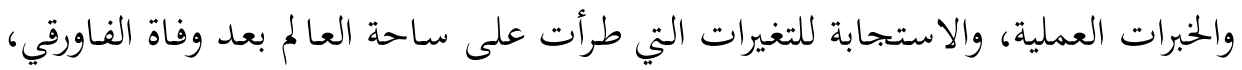

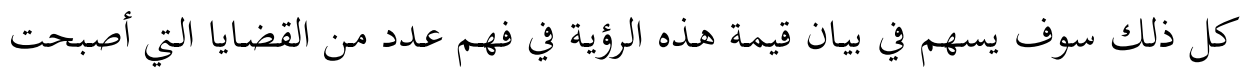

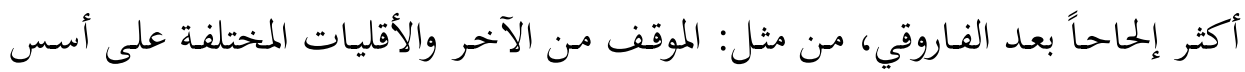
أخرى غير الدين والطائفة، والموقف من الإرهاب، والعدالة والمساواة في العلاقات الدولية

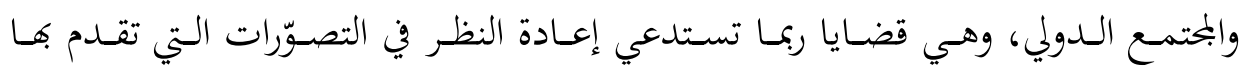
الفاروقي حول طبيعة الدولة، وطبيعة النظام الدولي. 